\title{
AMMA galardona la excelencia y la innovación en la práctica profesional de la museología y la museografía en Andalucía
}

La Asociación de Museólogos y Museógrafos de Andalucía (AMMA) ha lanzado en 2021 los premios EXPONE a las buenas prácticas e innovación en museos y exposiciones de Andalucía. Conscientes de cómo se han transformado las dinámicas de difusión del patrimonio cultural ante las dificultades sobrevenidas por la crisis sanitaria mundial, la AMMA quiere reconocer con este premio independiente, el valor, el esfuerzo y la excelencia en la práctica profesional de la museología y la museografía a los museos y centros expositivos andaluces, dar visibilidad a los proyectos desarrollados, presentarlos ante el público y distinguir a los profesionales del sector.

Santiago Campuzano Guerrero | Gestor cultural y museólogo

M. ${ }^{a}$ Dolores Cebrián Sotomayor | Mediadora cultural

Elena López Gil | Museógrafa

Sol Martín | Gestora cultural y museóloga

URL de la contribución <http://www.iaph.es/revistaph/index.php/revistaph/article/view/5008>

Con las cinco categorías convocadas por los premios EXPONE (premio especial del público, a la mejor estrategia de comunicación, a la mejor exposición virtual, a la mejor exposición, y honorífico a la mejor trayectoria profesional), la Asociación de Museólogos y Museógrafos de Andalucía (AMMA) ha querido reconocer la calidad en el enfoque del proyecto, el grado de consecución de los objetivos propuestos, la adecuación al contexto y lo oportuno que ha sido su desarrollo.

\section{Premio especial del público}

Los destinatarios finales, los visitantes, votaron este premio, ya que son el centro de todo buen proyecto y los que le dan sentido. El público también ha tenido que adaptarse a los nuevos tiempos y convertirse en "público digital", participando muy activamente en las redes sociales.

Por la reflexión que ofrece sobre el paisaje, y por la capacidad de aglutinar en un mismo proyecto la visión creativa del arte actual con las particularidades del enclave arqueológico en el que se desarrolla, el público decidió que merecía ser galardonada en esta categoría la exposición La filosofía del paseante, organizada por el Conjunto Arqueológico de Baelo Claudia con obras del artista Román Lokati.

\section{Premio a la mejor estrategia de comunicación}

Este premio reconoce la labor de comunicación que han desarrollado los y las profesionales que, detrás de webs, redes sociales, noticias en prensa y actividades, buscan y piensan en la mejor manera de llegar al público. Han tenido que transformarse más que cualquier otro perfil profesional $y$, a veces, lo han hecho con más voluntad que medios, por eso es doblemente importante resaltar esta categoría.

Por su capacidad para reelaborar los códigos relacionales desde el ámbito de la comunicación, por su permeabilidad a unos públicos que demandaban nuevas formas de seguir presentes en el museo, y por su agilidad a la hora de responder ante la nueva situación, el premio para a la mejor estrategia de comunicación fue otorgado al Museo de Bellas Artes de Sevilla y su apuesta por lo digital.

\section{Premio a la mejor exposición virtual}

Se dirige a las nuevas maneras de generar conocimiento que han proliferado en nuestros museos desde el primer confinamiento por la crisis sanitaria en marzo de 2020 , que conllevó el cierre de museos y centros de exposiciones. Con las exposiciones virtuales se ha conseguido 

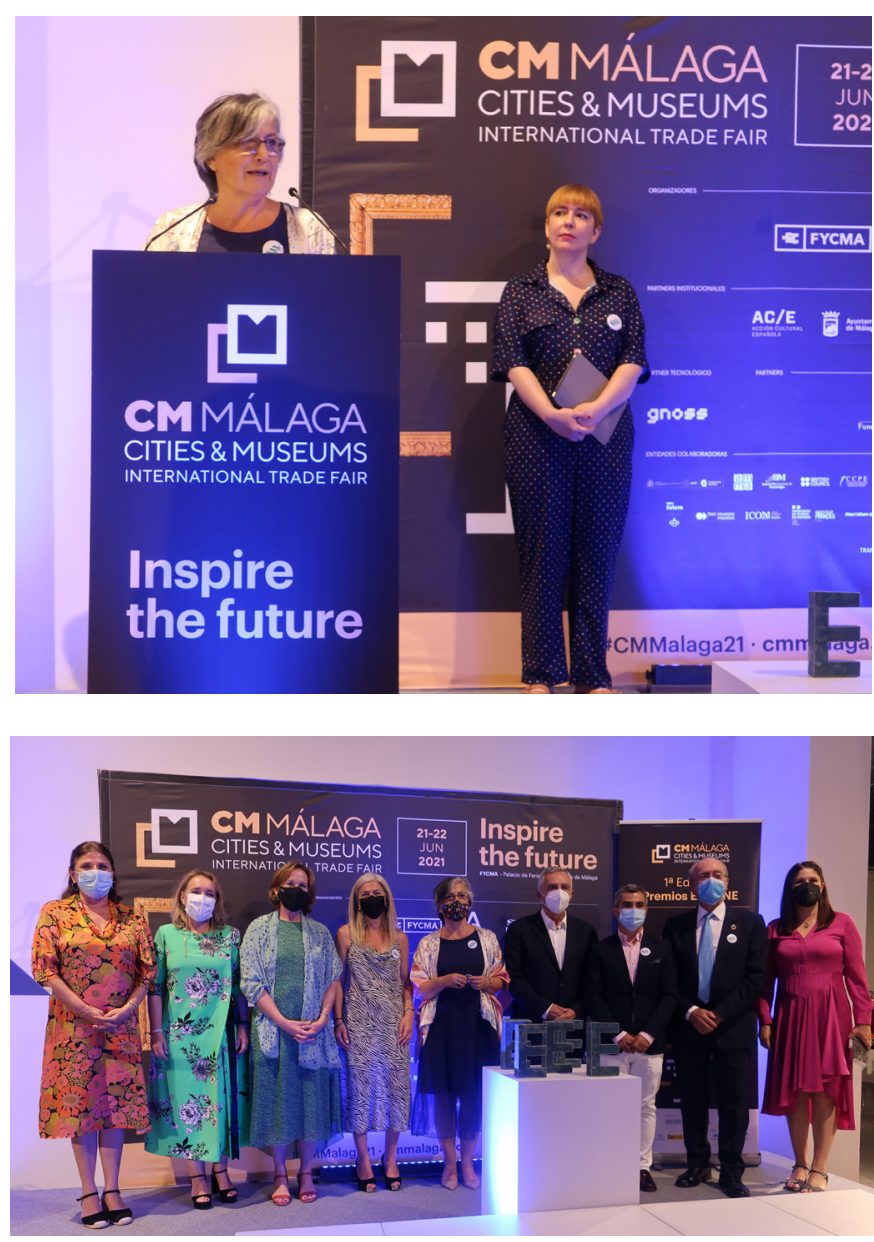

Entrega de los premios EXPONE 2021. Arriba, Elena López Gil, presidenta de la AMMA. Debajo, autoridades asistentes al acto, junto con los galardonados | fotos Asociación de Museólogos y Museógrafos de Andalucía

trasladar los contenidos de las colecciones al interior de los hogares de los visitantes, rompiendo cualquier tipo de barrera y límite geográfico o temporal. Y todo parece indicar que estos nuevos públicos y estas nuevas formas de asistir a una exposición van a quedarse y revolucionar para siempre la esfera expositiva.

Por llevar a su comunidad el resultado de una ardua investigación y de una extraordinaria interpretación del yacimiento arqueológico, por permitir la comprensión del bien y garantizar el acceso público a la información, el premio a la mejor exposición virtual se concede a la Recreación 3D de la villa romana del Salar, proyecto de la Delegación Territorial de Fomento, Infraestructuras, Ordenación del Territorio, Cultura y Patrimonio Histórico en Granada.

\section{Premio a la mejor exposición}

Este galardón distingue uno de los lenguajes predilectos que la museología dispone para contar historias y desarrollar los argumentos que permitirán al público acceder al conocimiento y enamorarse de los relatos: las exposiciones presenciales. En los últimos tiempos "lo presencial" ha tenido que sortear escenarios jamás previstos y esta situación ha llevado a la comunidad profesional encargada cargo de museos y centros de exposiciones a sacar lo mejor de sí misma.

Por su apuesta por un modelo de gestión cultural de calidad y sostenible en el municipio, por las altas cuotas de participación ciudadana conseguida - hasta el punto de que todos los vecinos forman parte activa del proyectoy por su singularidad -es considerado el único pueblo museo del mundo- el proyecto ganador en esta categoría es Genalguacil, pueblo museo.

\section{Premio honorífico a la trayectoria profesional}

Destinado a reconocer la trayectoria de alguien para quien los museos, el arte y la creación han sido una constante en su vida, y su vida una constante en los museos. En esta primera edición de los premios EXPONE, la AMMA se ha sentido muy honrada de reconocer con el premio EXPONE Honorífico a la trayectoria profesional a José Lebrero Stals, actual director del Museo Picasso Málaga. Por la excelencia de su carrera investigadora, por la extraordinaria capacidad de imprimir carácter y profundidad a las instituciones que ha dirigido y por la altísima calidad de las exposiciones que ha comisariado.

La entrega de los galardones correspondientes a esta primera edición tuvo lugar en un acto celebrado en la feria internacional CM Málaga-cities \& museums 2021. 